\title{
Dynamic and thermodynamic contributions to Northern China dryness in El Niño developing summer
}

\author{
Shujie Liu, ${ }^{1} \mathrm{Na}$ Wen,,${ }^{1, *}$ and Laurent $\mathrm{Li}^{3}$ \\ ${ }^{1}$ College of Atmospheric Sciences, Nanjing University of Information Science and \\ Technology, Nanjing 210044, China \\ ${ }^{2}$ Key Laboratory of Meteorological Disaster of Ministry of Education, Nanjing \\ University of Information Science and Technology, Nanjing 210044, China \\ ${ }^{3}$ Laboratoire de Météorologie Dynamique, CNRS, Sorbonne Université, Ecole Normale \\ Supérieure, Ecole Polytechnique, Paris 75005, France
}

\author{
*Corresponding author: \\ Dr. Na Wen \\ College of Atmospheric Sciences, Nanjing University of Information Science \& \\ Technology, Nanjing 210044, China; \\ E-mail:wenna@nuist.edu.cn
}

\begin{abstract}
In El Niño developing summer, Northern China shows reduced precipitation. The underlying mechanism is investigated through an analysis on the regional moisture and moist static energy budget. It is shown that the thermodynamic effect in relation to water vapor changes increases the regional wetness, but it is much smaller than the dynamic effect in relation to anomalies of atmospheric circulation. The anomalous vertical descent term is particularly pronounced. This anomalous vertical motion is mainly constrained by the horizontal advection of climatological moist enthalpy by anomalous wind, with a deficit of moist static energy in the region. A descent is then produced to compensate the energy lose and leads to dryness. Further investigation shows that an El Niño-induced anomalous cyclone over Northeast Asia is the main ingredient in controlling the dynamic effect for both water vapor budget and moist static energy budget.
\end{abstract}

Key Words: Precipitation deficit; El Niño developing summer; Moist static energy; Dynamic effect; Thermodynamic effect 


\section{Introduction}

Precipitation in Northern China, mainly occurring in the summer monsoon season, is strongly modulated by the El Niño Southern Oscillation (ENSO) at interannual time scale (Nitta, 1987; Sun and Sun, 1994; Zhang et al., 1999; Feng et al., 2010; Yuan and Yang, 2012; Zhou et al., 2014; Wang et al., 2017). Dry conditions are generally observed when El Niño occurs in the Tropical Pacific (Huang and Wu, 1989; Wu et al., 2003; Chen et al., 2006; Wen et al., 2015; Zhang et al., 2018; Zhang et al., 2019). A few studies reported that ENSO-associated sea surface temperature (SST) anomalies in the Tropical Pacific can affect the position and intensity of the western Pacific subtropical high which largely controls the advance and retreat of the East Asian summer monsoon, and ultimately modulate the rainfall in Northern China (Huang and Wu, 1989; Chen, 2002; Huang et al., 2004; Hao and Ding, 2012; Xue et al., 2018). Although the role played by changes of the regional atmospheric circulation in the reduction of rainfall in Northern China was well recognized (Wu et al., 2003; Wen et al., 2019), we still don't know what is the operational mode. Its quantitative contribution still needs to be assessed. According to Wen et al. (2019) who studied precipitation anomalies in China in the summer preceding the mature phase of El Niño, the reduction of precipitation in Northern China is associated with the El Niño-induced anomalous cyclone over East Asia.

In this paper, we pursue the work of Wen et al. (2019), by using a diagnostic tool to assess how dynamic and thermodynamic processes contribute to the precipitation reduction in Northern China in El Niño-developing summer. The tool is based on an analysis of the budget equation of water vapor (Chou and Neelin, 2003; Chen and Bordoni, 2014) and moist static energy (Neelin and Held, 1987; Neelin, 2007). It was widely used in a variety of applications to understand climate variation in China for future evolution (Yao et al., 2017), as well as for paleoclimate (Sun et al., 2016, 2018). As in Wen et al. (2019), we also restricted our investigation to the summer preceding the mature phase of an ENSO event. This choice was motivated by the fact that, during the El Niño-developing summer, SST anomalies from other oceanic basins are not yet significant, and the relevant climate driver is essentially the SST anomalies from the tropical Pacific, as shown in Fig. 1a. The main feature of precipitation anomaly in East Asia is the negative precipitation anomaly in Northern China (black dashed box in Fig. 
1b). The objective of our study is thus to search a relevant mechanism allowing to explain the precipitation reduction in Northern China in El Niño developing summer.

The rest of the paper is organized as follows. Section 2 describes the datasets, analysis methods, and the selection of El Niño/La Niña events used in the study. Section 3 presents the dynamic and thermodynamic contributions to dryness in Northern China during El Niño developing summer. Section 4 summarizes the major conclusions and presents a short discussion on the similarity and difference between the ENSO-induced rainfall deficit in Northern China and that occurring in summers without ENSO events identified.

\section{Datasets and methods}

\subsection{Datasets}

The data used in this study include monthly-mean gauge-based precipitation in China, global SST and relevant atmospheric variables from a re-analysis product. The monthly precipitation dataset compiled from 160 stations covering mainland China is provided by the National Climate Center, China Meteorological Administration (CMA). Monthly SST is from the Met Office Hadley Centre Sea Ice and SST dataset (HadISST, Rayner et al., 2003), with horizontal resolution at $1^{\circ} \times 1^{\circ}$. Relevant atmospheric variables, such as wind, temperature, specific humidity, geopotential height, and surface heat fluxes, are extracted from the Japanese 55-year Reanalysis (JRA-55, Ebita et al., 2011) performed by Japan Meteorological Agency (JMA), with horizontal resolution at $1.25^{\circ} \times 1.25^{\circ}$. All datasets cover the common period from 1963 to 2012 . El Niño and La Niña events were selected as in Wen et al. (2019). Only strong events are considered, as shown in Table 1.

\subsection{Methods}

\subsubsection{Moisture budget diagnosis}

The moisture budget equation is used to assess physical mechanisms responsible of precipitation changes in Northern China. Its vertically-integrated form for a whole air column can be expressed as:

$$
\left\langle\partial_{t} q\right\rangle+\left\langle\vec{V}_{H} \cdot \nabla_{h} q\right\rangle+\left\langle\omega \cdot \partial_{p} q\right\rangle=E-P
$$

where $q$ denotes specific humidity; $\vec{V}_{H}$ and $\omega$ represent horizontal wind and vertical 
pressure velocity, respectively; $E$ and $P$ denote evaporation and precipitation, respectively; and angle brackets $(\langle\rangle)$ denote a mass integral through the entire troposphere.

If we ignore the time tendency term that is generally much smaller at interannual time scale, and take the derivative (noted by a prime) for Eq. (1), we can then deduce the budget equation controlling anomalous variables, namely, the anomalies of El Niño cases deviated from long-term climatology. We can furthermore decompose the horizontal and vertical advection terms into linear terms and a residual:

$$
P^{\prime}=E^{\prime}-\left\langle\bar{\omega} \partial_{p} q^{\prime}\right\rangle-\left\langle\omega^{\prime} \partial_{p} \bar{q}\right\rangle-\left\langle{\overrightarrow{\vec{V}_{H}}}_{H} \cdot \nabla q^{\prime}\right\rangle-\left\langle\vec{V}_{H}{ }^{\prime} \cdot \nabla \bar{q}\right\rangle+\operatorname{Res}
$$

where the overbars $\left(^{-}\right)$denote monthly mean, the primes $\left(^{\prime}\right)$ represent monthly anomaly, and Res includes non-linear residual term. The two terms involving horizontal and vertical advection of anomalous moisture by climatological wind $\left(\left\langle-\overrightarrow{\vec{V}}_{H} \cdot \nabla q^{\prime}\right\rangle\right.$ and $\left.\left\langle-\bar{\omega} \partial_{p} q^{\prime}\right\rangle\right)$ are generally referred to as thermodynamic contributions, moisture being considered as a thermodynamic variable. Similarly, the two terms involving advection of climatological moisture by anomalous wind $\left(\left\langle-\omega^{\prime} \partial_{p} \bar{q}\right\rangle\right.$ and $\left.\left\langle-\vec{V}_{H}{ }^{\prime} \cdot \nabla \bar{q}\right\rangle\right)$ are referred to as dynamic contributions (in relation to atmospheric circulation).

\subsubsection{Moist static energy diagnosis}

Eq. (2) provides us an efficient way to understand precipitation anomalies, but we have to find an additional equation to constrain the anomalous vertical motion which generally plays a dominant role for precipitation (Rose and Lin, 2003). This can be achieved from the perspective of energy balance. Moist static energy (MSE) budget analysis is a useful tool for quantifying the roles of specific humidity, temperature, large-scale circulation, and radiative processes in the spatial distribution of rainfall related to changes of vertical motion (Neelin, 2007; Chou et al., 2013; Chen and Bordoni, 2014; Sun et al., 2016). So, we adopted the MSE equation in our work, as inspired from $\mathrm{Wu}$ et al. (2017). It can be written as

$$
\left\langle\partial_{t}\left(c_{v} T+L_{v} q\right)\right\rangle+\left\langle\vec{V}_{H} \cdot \nabla M\right\rangle+\left\langle\omega \partial_{p} h\right\rangle=F_{n e t}
$$

where $M=c_{p} T+L_{v} q$ is moist enthalpy (dry enthalpy plus latent energy); MSE is represented by $h=c_{p} T+L_{v} q+\phi$ (dry enthalpy, latent energy and potential energy); $c_{p}$ and $c_{v}$ denote the specific heat at constant pressure and constant volume, 
respectively; $L_{v}$ is the latent heat of vaporization; $T$ denotes air temperature; $\phi$ denotes the geopotential; and $F_{\text {net }}$ is the net energy entering the atmospheric column, which includes sensible heat, latent heat, and shortwave and longwave radiative fluxes at the surface and top of atmosphere (Wu et al., 2017).

Similar to the manipulation applied to the moisture equation, we can neglect the time tendency term, make the derivative to obtain anomalous variables (noted by primes), and decompose the advection term. The anomalous MSE equation can be expressed as:

$$
\left\langle\omega^{\prime} \partial_{p} \bar{h}\right\rangle=F_{n e t}^{\prime}-\left\langle\overline{\vec{V}}_{H} \cdot \nabla M^{\prime}\right\rangle-\left\langle\vec{V}_{H}{ }^{\prime} \cdot \nabla \bar{M}\right\rangle-\left\langle\bar{\omega} \partial_{p} h^{\prime}\right\rangle+R e s
$$

With a given profile of $\bar{h}$, this equation provides a powerful diagnostic for the anomalous vertical motion $\omega^{\prime}$. Similar to the convention used for moisture decomposition, the two terms involving anomalous MSE and moist enthalpy are called thermodynamic contributions $\left(\left\langle-\overline{\vec{V}}_{H} \cdot \nabla M^{\prime}\right\rangle\right.$ and $\left.\left\langle-\bar{\omega} \partial_{p} h^{\prime}\right\rangle\right)$, while the two terms involving anomalous atmospheric circulation are called dynamic contributions $\left(\left\langle-\omega^{\prime} \partial_{p} \bar{h}\right\rangle\right.$ and $\left.\left\langle-\vec{V}_{H}{ }^{\prime} \cdot \nabla \bar{M}\right\rangle\right)$.

\section{Results}

\subsection{Conditions leading to dryness in Northern China}

Results from the moisture balance analysis (Eq. (2)) are displayed in Fig. 2a for areal averages in Northern China corresponding to El Niño developing summer. Consistent with previous studies (Huang and Wu, 1989; Chen, 2002; Wu et al., 2003; Wen et al., 2019), there are dry conditions with reduced precipitation. The evaporation term and that of the mean vertical transport of anomalous water vapor are both very small. The reduced precipitation (Fig. 2a) is mainly caused by negative anomalous vertical advection of climatological moisture by descending anomalies $\left\langle-\omega^{\prime} \partial_{p} \bar{q}\right\rangle$ and negative anomalous horizontal advection of climatological moisture by anomalous horizontal wind $\left\langle-\vec{V}_{H}{ }^{\prime} \cdot \nabla \bar{q}\right\rangle$, while advections of anomalous moisture by climatological horizontal wind $\left\langle-{\overrightarrow{\vec{V}_{H}}} \cdot \nabla q^{\prime}\right\rangle$ and vertical motion $\left\langle-\bar{\omega} \partial_{p} q^{\prime}\right\rangle$ have opposite contributions to increase precipitation in Northern China. As a whole, the dynamic effect overpasses largely the thermodynamic effect, which finally causes the decrease of precipitation in Northern China. For the two dynamic contributions, the horizontal term 
$\left\langle-\vec{V}_{H}{ }^{\prime} \cdot \nabla \bar{q}\right\rangle$ is smaller than the vertical term $\left\langle-\omega^{\prime} \partial_{p} \bar{q}\right\rangle$, which was expected due to the very large water vapor gradient in the vertical. For the two terms of thermodynamic contribution, the vertical component is surprisingly very small, which reveals certainly a homogenous change of water vapor in the vertical. Since the vertical motions are constrained by the MSE budget balance, Back and Bretherton (2009) pointed out that descending anomalies tend to compensate the energy reduction of the atmospheric column in deep convection regions, that is, the anomalous vertical advection of the climatological MSE $\left\langle-\omega^{\prime} \partial_{p} \bar{h}\right\rangle$ is generally positive.

The anomalous descent in Northern China, causing local precipitation decrease, is consistent with the MSE budget analysis (Fig. 2b) which results in a reduction of $\left\langle\omega^{\prime} \partial_{p} \bar{h}\right\rangle$. Fig. 3a displays the vertical profiles of $\omega^{\prime}$ and $\bar{h}$. In Northern China, the vertical profile of $\omega^{\prime}$ presents a top-heavy bow structure with a maximum at about 400-hPa, and the vertical profile of climatological MSE $h$ shows a bottom-heavy bow structure with a maximum at $600-\mathrm{hPa}$ (Fig. 3a). Because the MSE stratification is generally negative in the stable troposphere $\left\langle\partial_{p} \bar{h}\right\rangle<0$ (Chou et al., 2013; Chen and Bordoni, 2014), a region of negative $\left\langle\omega^{\prime} \partial_{p} \bar{h}\right\rangle$ represents descending anomalies $\left(\omega^{\prime}\right\rangle$ $0)$, and a region of positive $\left\langle\omega^{\prime} \partial_{p} \bar{h}\right\rangle$ implies ascending anomalies. Meanwhile, the vertical profile of $h^{\prime}$ shows a bottom-heavy bow structure with a maximum at $850-\mathrm{hPa}$ (Fig. 3b). Among the three terms included in $h^{\prime}, g z^{\prime}$ is small, $h^{\prime}$ approaches $L_{v} q^{\prime}$ in low level, but $c_{p} T^{\prime}$ above $650-\mathrm{hPa}$. The vertical structure of $\bar{\omega}$ shows positive values in middle and negative values at high level and near the surface, which makes $-\left\langle\bar{\omega} \partial_{p} h^{\prime}\right\rangle$ very small.

It is also clear that this descent is primarily caused by negative anomalies of the horizontal advection of climatological moist enthalpy by anomalous wind $\left\langle-\vec{V}_{H}{ }^{\prime} \cdot \nabla \bar{M}\right\rangle$, but alleviated by positive anomalies of the horizontal advection of anomalous moist enthalpy by climatological wind $\left\langle-\overrightarrow{\vec{V}}_{H} \cdot \nabla M^{\prime}\right\rangle$. Again, the thermodynamic effect is opposed to the dynamic effect, but is insufficient to reverse the dynamic effect which provokes regional descending motions. In the following, we will see that such a situation is achieved by changes in water vapor content (thermodynamic effect) and atmospheric circulation (dynamic effect). 


\subsection{Spatial distribution of the moist static energy balance}

To further describe the physical mechanisms responsible for the MSE balance, spatial distributions of each term in MSE equation are shown (Fig. 4). They are consistent with the regional averages. Since $\left\langle\partial_{p} \bar{h}\right\rangle$ is generally negative in a stable troposphere, the negative precipitation anomaly in Northern China (Fig. 1b) implies that the $\left\langle\omega^{\prime} \partial_{p} \bar{h}\right\rangle$ term is negative (Fig. 4a), which produces anomalous descending motions. Thus, it can be seen in Fig. 4a that, the maximum center of descending is located in the south of the area (black dashed box in Fig. 4a), where the maximum center of precipitation reduction (Fig. 1b) is larger.

We pursue now our analyses on different terms on the right side of Eq. (5). In East Asia, the net energy flux $F_{\text {net }}^{\prime}$ and climatological vertical advection of anomalous MSE $-\left\langle\bar{\omega} \partial_{p} h^{\prime}\right\rangle$ are small. And the horizontal advection of anomalous moist enthalpy by climatological wind $\left\langle-{\overrightarrow{\vec{V}_{H}}}_{H} \cdot \nabla M^{\prime}\right\rangle$ has a negative contribution to $\left\langle\omega^{\prime} \partial_{p} \bar{h}\right\rangle$. The horizontal advection of climatological moist enthalpy by anomalous wind $\left\langle-\vec{V}_{H}{ }^{\prime} \cdot \nabla \bar{M}\right\rangle$ in Northern China is very significant, which plays a dominant role in balancing $\left\langle\omega^{\prime} \partial_{p} \bar{h}\right\rangle$. The effect of $\left\langle-\vec{V}_{H}{ }^{\prime} \cdot \nabla \bar{M}\right\rangle$ is obviously in the whole domain of Northern China, especially in the north part, with maximum values reaching more than $-15 \mathrm{~W} / \mathrm{m}^{2}$. Thus, the energy suppressing convection over Northern China is mainly contributed by the horizontal moist enthalpy advection.

\subsection{Dynamic effect}

From the above MSE budget analysis, the horizontal advection of climatological moist enthalpy by anomalous wind is revealed to be the most important contributor to the anomalous vertical advections of climatological MSE in northern China (Fig. 2b, Fig. 4e). The moist enthalpy $M=c_{p} T+L_{v} q$ is a function of temperature and specific humidity, hence we decompose the horizontal advection of climatological moist enthalpy by anomalous wind into two parts in relation to dry enthalpy $\left\langle-\vec{V}_{H}{ }^{\prime} \cdot \nabla c_{p} \bar{T}\right\rangle$ (Fig. 5a), and to latent heat $\left\langle-\vec{V}_{H}{ }^{\prime} \cdot \nabla L_{v} \bar{q}\right\rangle$ (Fig. 5b). It can be seen that the contribution of the horizontal transport of enthalpy by anomalous wind is more important. It is significantly negative in Northern China, and it has the lowest value about $-15 \mathrm{~W} / \mathrm{m}^{2}$ in the northeast of Northern China. That is, there is strong cold air (low enthalpy) transport 
to the area. Another term $\left\langle-\vec{V}_{H}{ }^{\prime} \cdot \nabla L_{v} \bar{q}\right\rangle$ with the lowest value about $-9 \mathrm{~W} / \mathrm{m}^{2}$ in the west of Northern China. This term can also be regarded as $\left\langle-\vec{V}_{H}{ }^{\prime} \cdot \nabla \bar{q}\right\rangle$ in Eq. (2), which can explain the dryness in the north of Northern China, mainly caused by the horizontal advection of dry air. In order to enhance our understanding on the transport of enthalpy or latent heat by anomalous wind, we can divide the anomalous wind into two parts, following zonal and meridional directions respectively (middle and right panels in Fig. $5)$.

In Northern China, there is a notable transport of cold air by anomalous northerly wind. As compared in Fig. 5c and Fig. 5e, the meridional anomalous wind has a dominant effect. This is partly related to the spatial distribution of climatological temperature which is generally warm in south and cold in north to create a strong meridional gradient in Northern China. It is easy to conclude that anomalous northerly winds transport cold air to Northern China, and make the atmosphere column lose its energy. The MSE balance imposes a descending motion to warm up the atmosphere column and to reduce the energy losing in the atmosphere column, resulting ultimately in dryness.

The advection of climatological latent heat by zonal and meridional anomalous winds is displayed in Fig. 5d and Fig. 5f, respectively. Similar to enthalpy advection, it is also obvious that the meridional anomalous wind has a dominant role on the advection of climatological latent heat. This is also related to the spatial distribution of climatological specific humidity with sharp north-south gradient in Northern China. Beyond the descending-motion effect deduced from the MSE constraint, this term of latent heat advection can actually represent the water vapor transport $\left\langle-\vec{V}_{H}{ }^{\prime} \cdot \nabla \bar{q}\right\rangle$ in Eq. (2). It can directly affect the precipitation, dry air advection leading to dryness in Northern China.

\subsection{Thermodynamic effect}

In addition to the dynamic effect of horizontal advection of climatological moist enthalpy by anomalous wind, the thermodynamic effect of horizontal advection of anomalous moist enthalpy by climatological wind shows anti-contribution in the MSE analysis (Fig. 4d). In order to compare the thermodynamic and dynamic effects, the analysis is pursued. Similar to horizontal advection by anomalous wind, the horizontal 
advection of anomalous moist enthalpy by climatological wind, forming the thermodynamic effects, can also be divided into two parts in relation to dry enthalpy $\left\langle-\overrightarrow{\vec{V}}_{H} \cdot \nabla c_{p} T^{\prime}\right\rangle$ (Fig. 6a), and to latent heat $\left\langle-\overline{\vec{V}}_{H} \cdot \nabla L_{v} q^{\prime}\right\rangle$ (Fig. 6b). $\left\langle-\overline{\vec{V}}_{H} \cdot \nabla L_{v} q^{\prime}\right\rangle$ is

positive in Northern China, another term $\left\langle-\overline{\vec{V}}_{H} \cdot \nabla c_{p} T^{\prime}\right\rangle$ is also positive in Northern China, but failed the significance test.

In order to enhance our understanding, we divide the climatological wind into two parts, following zonal and meridional directions respectively. The advection of anomalous latent heat by zonal and meridional climatological winds is shown in Fig. 6d and Fig. 6f, respectively. These terms of latent heat advection can actually represent the moisture transport $\left\langle-\vec{V}_{H} \cdot \nabla q^{\prime}\right\rangle$ in Eq. (2). Different from anomalous wind transport showing a dominant meridional component, the zonal component of the thermodynamic effect is the dominant one. The dominant climatological westerly wind, combined with anomalies of water vapor in this region (shown later) can well explain the spatial structure of the thermodynamic effect which humidifies Northern China. It would directly increase precipitation in Northern China. But the thermodynamic effect increasing the regional precipitation is much smaller than the dynamic effect reducing it.

The advection of anomalous dry enthalpy by zonal and meridional climatological winds is displayed in Fig. $6 \mathrm{c}$ and Fig. 6e, respectively. It is obvious that the zonal component has a dominant role on the advection of anomalous enthalpy. It is coherent with the climatological westerlies combined with the regional anomalous structures of temperature (shown later). Such a combination increases MSE in Northern China and causes ascending motions, beneficial to regional precipitation. However, this advection by climatological wind (thermodynamic effect) is much smaller compared to the advection by anomalous wind (dynamic effect).

\subsection{Regional atmospheric circulation patterns}

To verify the consistency of MSE transport with the regional atmospheric general circulation, Fig. 7a, 7b display the spatial distribution of composite vertical integrated anomalous wind (vectors) and climatological temperature (red shading) and specific humidity (blue shading). It can be seen that, in El Niño developing summer, there is an obvious anomalous cyclone over Northeast Asia. Northern China is situated in the 
southwest of this anomalous cyclone with northerly wind anomalies. The climatological isotherm lines over East Asia are roughly zonally distributed (Fig. 7a, shading), with warm air in south and cold air in north. There is a dense isotherm gradient in the north of the studied area. Consequently, the anomalous northerly wind on the west side of the anomalous cyclone (Fig. 7a, vector) can efficiently advect cold air (low enthalpy) to Northern China. Similarly, the climatological specific humidity over East Asia decreases from south to north (Fig. 7b, shading), with an obvious negative meridional gradient. Therefore, the anomalous northerly wind branch (Fig. 7b, vector) carries dry air (low latent energy) to Northern China. This indicates that the anomalous cyclone over Northeast Asia leads to dryness in northern China, which is consistent with the results of $\mathrm{Wu}$ et al. (2003) and Wen et al. (2019). This atmospheric circulation pattern seems an important player regulating the regional climate variation. Several other studies also revealed the prominent role of a 'stationary eddy' over East Asia in global warming scenarios and in paleoclimate simulations (Sun et al., 2016, 2018).

Fig. 7c, 7d display the spatial distribution of vertical integrated climatological wind (vector), air temperature anomaly (shading) and specific humidity anomaly (shading). It can be seen that air temperature and specific humidity decrease in Northern China. The gradient of air temperature and specific humidity are both positive in the main airflow direction in Northern China, but the gradients are small. This is why the thermodynamic effect is weak.

\subsection{Teleconnection linking Asian anomalous circulations to the tropical Pacific}

It is now clear that the cyclonic circulation over Northeast Asia is the key to explain the dryness in Northern China through its dynamic and thermodynamic contributions in the El Niño developing summer. Remote impacts of the tropical Pacific SST anomalies to Northeast Asia seems undoubtful, since no other significant SST anomalies are observed for the developing stage of El Niño (as shown in Fig. 1a). But we still need to investigate how this cyclonic structure is remotely generated and maintained by SST anomalies in the tropical Pacific.

To do so, we performed a composite analysis, as in Wen et al. (2019), for the atmospheric anomalous circulation at low and high levels (Fig. 8). The analysis is applied to all events listed in Table 1. At the upper level (200-hPa), we can observe a canonical Gill-type (Gill, 1980) response with two anticyclonic circulation patterns over 
the tropical central Pacific on each side of the equator (accompanied by ascending motions at 500-hPa, as shown in Fig. 8a). They are both source areas of Rossby waves, able to dissipate the latent heat released by convections in the tropical Pacific to higher latitudes. There is an asymmetry between the two hemispheres, with the northern lobe much more developed and extended to the subtropical Northwest Pacific. Correspondingly at low level (wind field at 850-hPa, Fig. 8a), we can observe a wave train propagating northwestward and furthermore entering into the Asian land. This direct wave train is believed to play the key role conveying impacts of SST anomalies in the tropical Pacific to Northeast Asia with a cyclonic anomaly over the latter. This wave-train structure is also referred to as the Pacific-Japan teleconnection pattern (Kosaka and Nakamura, 2006, 2010; Kubota et al., 2015). Some authors also pointed out that air-sea interactions in the Western North Pacific are important processes to create and to maintain the Pacific-East Asian teleconnection (Wang et al., 2000; Wang and Zhang, 2002; Li et al., 2017).

Indirect ways are also possible to relay the tropical Pacific anomalies (in relation to anomalous latent heat release in the Central and Eastern Pacific) to mid and high latitudes. Wen et al. (2019) pointed out that the Eastern Pacific and the Eastern Atlantic are two privileged regions to excite Rossby waves and to dissipate energy from the tropics to extra-tropics. Actually, there are intrusions of westerlies (color shading in Fig. $8 b)$ into the tropics over these two oceanic basins, which creates favorable conditions to realize extra-tropical connections. Once perturbations enter into the westerly jet, they can circulate around the world following the wave guide of the westerly jet (Branstator, 2002). Anomalous circulations can be thus created and maintained over Northeast Asia. Wen et al. (2019) also pointed out a third pathway over the Indian sub-continent where latent heat release is enhanced while El Niño develops in the tropical Pacific. Perturbations from India enters easily into the westerly jet due to their geographic proximity. $\mathrm{Wu}$ et al. (2009) and Li et al. (2017) elaborated an alternative explanation involving the response of a Kelvin wave to enhance the subtropical high pressure over the Philippine Sea when there is diabatic heating over India.

\section{Summary and Discussion}

In boreal summer preceding El Niño peaks that generally occur in boreal winter, Northern China often observes dry climatic conditions. Although many investigations 
were reported for this issue, a convincing physical mechanism was still missing to explain the dryness in Northern China in El Niño developing summer. In this paper, we presented a diagnostic work based on observations covering the last 50 years. We selected the strongest El Niño/La Niña events that occurred from 1963 to 2012 to make a composite analysis of atmospheric conditions favorable for summer precipitation suppression in Northern China. Our analysis was based on the water vapor budget equation applied on the domain of Northern China. It can reveal interesting mechanisms about different dynamic and thermodynamic processes controlling the regional precipitation. This work is the first of its kind, and it was furthermore completed by an evaluation of the regional MSE budget which permits us to explain the causes of vertical motion anomalies. Major findings can be summarized as follows.

The changes of water vapor content and its spatial structure are in such a way that the thermodynamic effect contributes to ease precipitation in Northern China. However, the dynamic effect in relation to changes of atmospheric circulation suppresses precipitation in Northern China. This precipitation reduction is firstly caused by anomalous horizonal wind from north bringing dry air. It is also caused (even in a more important proportion) by an anomalous descent in Northern China. This change of vertical motion can be well explained through the use of MSE equation.

With decomposition of the MSE budget equation, the anomalous descent inducing dryness in Northern China is mainly related to changes of the horizontal advection of climatological dry enthalpy (Fig. 5a) and latent energy (Fig. 5b) by anomalous wind. A further decomposition shows that this advection variation is dominated by its meridional component. Such a change of MSE budget is consistent with an El Niño-induced anomalous cyclone over Northeast Asia, the associated northerly wind being located in Northern China. The northerly wind brings cold air (low dry enthalpy) and dry air (low latent energy) into Northern China, causing the net cooling and reducing the energy of the atmospheric column, resulting in descending anomalies to increase temperature to compensate the loss of energy, which leads to dryness. On the other hand, the thermodynamic component is not conducive to drought in Northern China, this is related to the increase of $q^{\prime}$ and $T^{\prime}$ gradient in the main airflow direction.

In this work, we focused on the role of El Niño in generating rainfall deficit in Northern China. A natural extension of our work would be to contrast our results with 
those excluding El Niño years but still generating dryness or wetness in Northern China. In Appendix, we present a preliminary investigation to address this issue by compositing the driest and wettest summers (Table A1) excluding El Niño years. Fig. A1 shows the budget analysis of water vapor and MSE in Northern China, as a counterpart of Fig. 2. It is clear that dryness in Northern China is still subject to descending motions, the descent is still dominated by the meridional dynamic effect (positive contribution) and the zonal thermodynamic effect (negative contribution). Fig. A2 shows the counterpart of Fig. 7a and 7b. It reveals fundamental differences in terms of regional atmospheric circulation changes. Dry conditions in Northern China occurring in years without El Niño show a typical situation of weaker summer monsoon, in relation to the presence of a cyclonic circulation over the Korean Peninsula and a southward shift of the Northwestern Pacific Subtropical High. While El Niño-induced dryness in Northern China is clearly associated to a cyclonic circulation over Northeast Asia, a consequence of the wave train emanated from the Tropical Pacific.

Finally, we should point out that our work presented here only analyzes the general signal of precipitation in northern China in El Niño developing summer, while a few studies indicate that different types of El Niño may produce different precipitation responses in China (Feng et al., 2010; Yuan and Yang, 2012; Chen et al., 2014; Wen et al., 2020). With this work and the diagnostic tools of water vapor and MSE budget as a starting point, we will pursue our investigation on precipitation anomalies in Northern China for different types of El Niño.

\section{Acknowledgements.}

This work is supported by the National Key Research and Development Program of China (Grant-2018YFC1507704) and the National Natural Science Foundation of China (Grant-41475089). The JRA-55 reanalysis data are obtained through https://jra.kishou.go.jp/JRA-55/. The rainfall data of meteorological stations are obtained through https://cmdp.ncc-cma.net/. The HadISST dataset are obtained through https://www.metoffice.gov.uk/hadobs/hadisst/.

\section{Appendix: Dry conditions in Northern China while El Niño excluded}

Beyond El Niño, dry summers in Northern China can independently occur. But there are different signatures despite the common dry feature. To demonstrate this issue, we firstly excluded years identified as El Niño/La Niña, and then selected 10 non-El 
Niño summers with significant precipitation anomalies (larger than one standard deviation, at least). Dry and wet years in Table A1 were then used for a composite analysis (dry minus wet), with results shown in Fig. A1 and A2.

\section{References}

Back LE, and Bretherton CS. (2009) A simple model of climatological rainfall and vertical motion patterns over the tropical oceans. Journal of Climate 22: 64776497. https://doi.org/10.1175/2009JCLI2393.1

Branstator G. (2002) Circumglobal teleconnections, the jet stream waveguide, and the North Atlantic Oscillation. Journal of Climate 15: 1893-1910. https://doi.org/10.1175/1520-0442(2002)015<1893:CTTJSW>2.0.CO;2

Chen J, and Bordoni S. (2014) Orographic effects of the Tibetan Plateau on the East Asian summer monsoon: An energetic perspective. Journal of Climate 27: 30523072. https://doi.org/10.1175/JCLI-D-13-00479.1

Chen W. (2002) Impacts of El Niño and La Niña on the cycle of the East Asian winter and summer monsoon. Chinese Journal of Atmospheric Sciences 26: 595-610. https://doi.org/10.3878/j.issn.1006-9895.2002.05.02 (in Chinese)

Chen W, Kang LH, and Wang D. (2006) The coupling relationship between summer rainfall in China and global sea surface temperature. Climatic Environmental Research 11: 259-269. https://doi.org/10.3878/j.issn.1006-9585.2006.03.02 (in Chinese)

Chen ZS, Wen ZP, Wu RG, Zhao P, and Cao J. (2014) Influence of two types of El Niños on the East Asian climate during boreal summer: a numerical study. Climate Dynamics 43: 469-481. https://doi.org/10.1007/s00382-013-1943-1

Chou C, and Neelin JD. (2003) Mechanisms Limiting the Northward Extent of the Northern Summer Monsoons over North America, Asia, and Africa. Journal of Climate 16: 406-425. https://doi.org/10.1175/1520-0442(2003)016<0406:mltneo>2.0.co;2

Chou C, Wu T, and Tan P. (2013) Changes in gross moist stability in the tropics under global warming. Climate Dynamics 41: 2481-2496. https://doi.org/10.1007/s00382-013-1703-2 
Ebita A, Kobayashi S, Ota Y, Moriya M, Kumabe R, Onogi K, Harada Y, Yasui S, Miyaoka K, Takahashi K, Kamahori H, Kobayashi C, Endo H, Soma M, Oikawa Y, and Ishimizu T. (2011) The Japanese 55-year Reanalysis "JRA-55": an interim report, SOLA, 7: 149-152. https://doi.org/10.2151/sola.2011-038

Feng J, Chen W, Tam C-Y, and Zhou W. (2010) Different impacts of El Niño and El Niño Modoki on China rainfall in the decaying phases. International Journal of Climatology 31: 2091-2101. https://doi.org/10.1002/joc.2217

Gill AE. (1980) Some simple solutions for heat-induced tropical circulation. Quarterly Journal of the Royal Meteorological Society 106: 447-462. https://doi.org/10.1002/qj.49710644905

Hao LS, and Ding YH. (2012) Progress of Precipitation Research in North China. Progress in Geography 31: 593-601. https://doi.org/10.11820/dlkxjz.(2012)05.007 (in Chinese)

Huang RH, Chen W, Yang BL, and Zhang RH. (2004) Recent advances in studies of the interaction between the East Asian winter and summer monsoons and ENSO cycle. Advances in Atmospheric Sciences 21: 407-424. https://doi.org/10.1007/BF02915568

Huang RH, and Wu YF. (1989) The Influence of ENSO on the summer climate change in China and its mechanisms, Advances in Atmospheric Sciences 6: 21-32. https://doi.org/10.1007/BF02656915

Kosaka Y, and Nakamura H. (2006) Structure and dynamics of the summertime PacificJapan teleconnection pattern. Quarterly Journal of the Royal Meteorological Society 132: 2009-2030. https://doi.org/10.1256/qj.05.204

Kosaka Y, and Nakamura H. (2010) Mechanisms of meridional teleconnection observed between a summer monsoon system and a subtropical anticyclone. Part I: the Pacific-Japan pattern. Journal of Climate 23: 5085-5108. https://doi.org/10.1175/2010JCLI3413.1

Kubota H, Kosaka Y, and Xie SP. (2015) A 117-year long index of the Pacific-Japan pattern with application to interdecadal variability. International Journal of Climatology 36: 1575-1589. https://doi.org/10.1002/joc.4441

Li T, Wang B, Wu B, Zhou TJ, Chang CP, and Zhang RH. (2017) Theories on formation of an anomalous anticyclone in western North Pacific during El Niño: A review. 
Journal of Meteorological Research 31: 987-1006. https://doi.org/10.1007/s13351-017-7147-6

Neelin JD, and Held IM. (1987) Modeling tropical convergence based on the moist static energy budget. Monthly Weather Review 115: 3-12. https://doi.org/10.1175/1520-0493(1987)115,0003:MTCBOT.2.0.CO;2

Neelin JD. (2007) Moist dynamics of tropical convection zones in monsoons, teleconnections, and global warming. The Global Circulation of the Atmosphere, T. Schneider and A. Sobel, Eds., Princeton University Press, Princeton, 267-301.

Nitta TS. (1987) Convective activities in the tropical western Pacific and their impact on the northern hemisphere summer circulation. Meteorological Society of Japan 65: 373-390. https://doi.org/10.2151/jmsj1965.65.3_373

Rayner NA, Parker DE, Horton EB, Folland CK, Alexander LV, Rowell DP, Kent EC, and Kaplan A. (2003) Global analyses of sea surface temperature, sea ice, and night marine air temperature since the late nineteenth century. Journal of Geophysical Research 108: 4407. https://doi.org/10.1029/2002JD002670

Rose BEJ, and Lin CA. (2003) Precipitation from vertical motion: A statistical diagnostic scheme. International Journal of Climatology 23: 903-919. https://doi.org/10.1002/joc.919

Sun Y, Ramstein G, Li L, Contoux C, Tan N, and Zhou TJ. (2018) Quantifying East Asian summer monsoon dynamics in the ECP4.5 scenario with reference to the Mid-Piacenzian warm period. Geophysical Research Letters 45: 12523-12533. https://doi.org/10.1029/2018GL080061

Sun BM, and Sun SQ. (1994) The analysis on the features of the atmospheric circulation in preceding winters for the summer drought and flooding in the Yangtze and Huaihe River Valley. Advances in Atmospheric Sciences 11: 79-90. https://doi.org/10.1007/BF02656997

Sun Y, Zhou TJ, Ramstein G, Contoux C, and Zhang ZS. (2016) Drivers and mechanisms for enhanced summer monsoon precipitation over East Asia during the mid-Pliocene in the IPSL-CM5A. Climate Dynamics 46: 1437-1457. https://doi.org/10.1007/s00382-015-2656-4

Wang B, Wu RG, and Fu XH. (2000) Pacific-East Asian teleconnection: How does ENSO affect East Asian climate? Journal of Climate 13: 1517-1536. 
https://doi.org/10.1175/1520-0442(2000)013<1517:PEATHD>2.0.CO;2.

Wang B, and Zhang Q. (2002) Pacific-East Asian teleconnection. Part II: How the Philippine Sea anomalous anticyclone is established during El Niño development. Journal of Climate 15: 3252-3265. https://doi.org/10.1175/1520-0442(2002)015<3252:PEATPI $>2.0 . C O ; 2$

Wang B, Juan LI, and Qiong HE. (2017) Variable and robust East Asian monsoon rainfall response to El Niño over the past 60 years (1957-2016). Advances in Atmospheric Sciences 34: 1235-1248. https://doi.org/10.1007/s00376-017-7016-3

Wen N, Liu ZY, and Liu YH. (2015) Direct impact of El Niño on East Asian summer precipitation in the observation. Climate Dynamics 44: 2979-2987. https://doi.org/10.1007/s00382-015-2605-2

Wen N, Liu ZY, and Li L. (2019) Direct ENSO impact on East Asian summer precipitation in the developing summer. Climate Dynamics 52: 6799-6815. https://doi.org/10.1007/s00382-018-4545-0

Wen N, Li L, and Luo JJ. (2020) Direct impacts of different types of El Niño in developing summer on East Asian precipitation. Climate Dynamics. https://doi.org/10.1007/s00382-020-05315-1

Wu B, Zhou TJ, and Li T. (2009) Seasonally evolving dominant interannual variability modes of East Asian climate. Journal of Climate 22: 2992-3005. https://doi.org/10.1175/2008JCLI2710.1

Wu B, Zhou TJ, and Li T. (2017) Atmospheric Dynamic and Thermodynamic Processes Driving the Western North Pacific Anomalous Anticyclone during El Niño. Part I: Maintenance Mechanisms. Journal of Climate 30: 9621-9635. https://doi.org/10.1175/JCLI-D-16-0489.1

Wu RG, Hu ZZ, and Kirtman BP. (2003) Evolution of ENSO-related rainfall anomalies in East Asia. Journal of Climate 16: 3742-3758. https://doi.org/10.1175/1520-0442(2003)016<3742:eoerai >2.0.co;2

Xue F, Duan XY, and Su TH. (2018) Comparison of intraseasonal variation of the East Asian summer monsoon between El Niño developing years and La Niña years. Climatic and Environmental Research 23: 321-331. https://doi.org/10.3878/j.issn.1006-9585.(2017)17044 (in Chinese)

Yao JC, Zhou TJ, Guo Z, Chen XL, Zou LW, and Sun Y. (2017) Improved performance 
of High-Resolution Atmospheric Models in simulating the East-Asian Summer Monsoon Rainbelt. Journal of Climate 30: 8825-8840. https://doi.org/10.1175/JCLI-D-16-0372.1

Yuan Y, and Yang S. (2012) Impacts of Different Types of El Niño on the East Asian Climate: Focus on ENSO Cycles. Journal of Climate 25: 7702-7722. https://doi.org/10.1175/jcli-d-11-00576.1

Zhang LX, Wu PL, Zhou TJ, and Xiao C. (2018) ENSO Transition from La Niña to El Niño Drives Prolonged Spring-Summer Drought over North China. Journal of Climate 31: 3509-352. https://doi.org/10.1175/JCLI-D-17-0440.1

Zhang LX, Zhou TJ, Wu PL, and Chen XL. (2019) Potential predictability of North China summer drought. Journal of Climate 32: 7247-7264. https://doi.org/10.1175/JCLI-D-18-0682.1.

Zhang RH, Sumi A, and Kimoto M. (1999) A diagnostic study of the impact of El Niño on the precipitation in China. Advances in Atmospheric Sciences 16: 229-241. https://doi.org/10.1007/BF02973084

Zhou TJ, Wu B, and Dong L. (2014) Advances in research of ENSO changes and the associated impacts on Asian-Pacific climate. Asia-Pacific Journal of Atmospheric Sciences 50: 405-422. https://doi.org/10.1007/s13143-014-0043-4 


\section{Captions:}

Table 1. Strong El Niño/La Niña cases (Wen et al. 2019) for composite analysis

\begin{tabular}{c|ccccccccccccc}
\hline Category & \multicolumn{10}{c}{ Events } \\
\hline El Niño & $1963 /$ & $1965 /$ & $1969 /$ & $1972 /$ & $1976 /$ & $1982 /$ & $1987 /$ & $1991 /$ & $1997 /$ & $2002 /$ & $2009 /$ \\
$(\mathbf{1 1})$ & 1964 & 1966 & 1970 & 1973 & 1977 & 1983 & 1988 & 1992 & 1998 & 2003 & 2010 \\
& & & & & & & & & & \\
La Niña & $1964 /$ & $1970 /$ & $1971 /$ & $1973 /$ & $1974 /$ & $1975 /$ & $1984 /$ & $1988 /$ & $1995 /$ & $1999 /$ & $2000 /$ & $2007 /$ & $2010 /$ \\
$(\mathbf{1 3})$ & 1965 & 1971 & 1972 & 1974 & 1975 & 1976 & 1985 & 1989 & 1996 & 2000 & 2001 & 2008 & 2011 \\
\hline
\end{tabular}



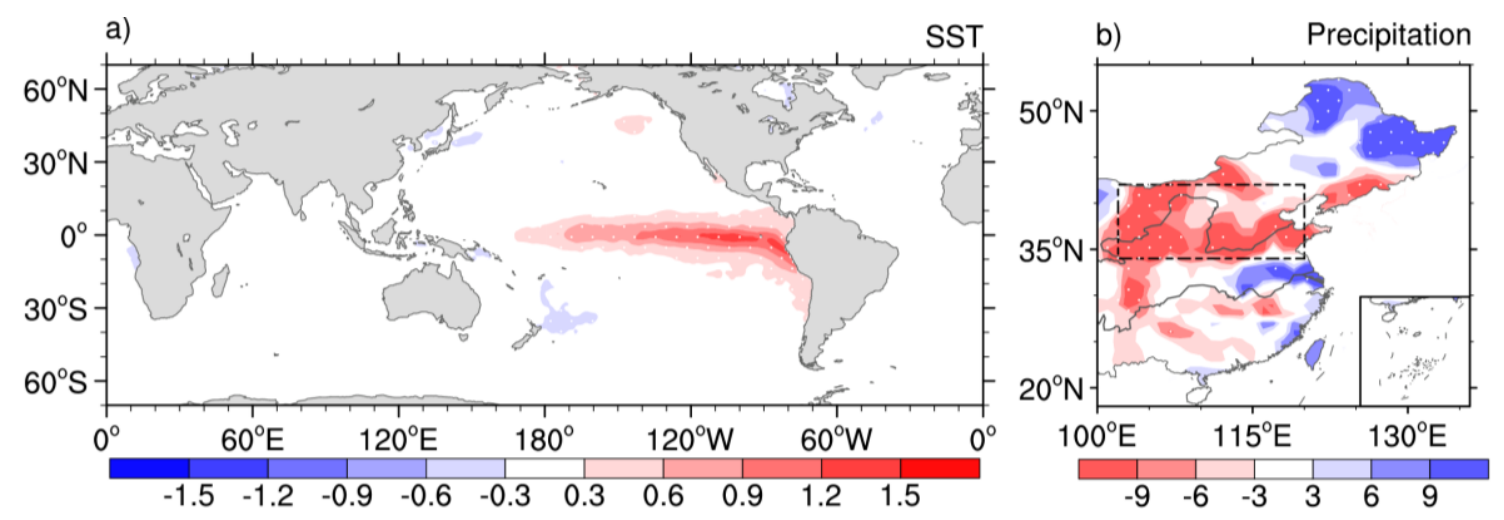

Fig. 1. Spatial distribution of the composite of (a) SST anomalies $\left({ }^{\circ} \mathrm{C}\right)$, and $(\mathrm{b})$ precipitation anomalies (relative values in \%) in Eastern China during El Niño developing summer. The location of the black dashed box in (b) is $34^{\circ} \sim 42^{\circ} \mathrm{N}$, $102^{\circ} \sim 120^{\circ} \mathrm{E}$. Values reaching the $10 \%$ significance level are stippled with dots.

a) Moisture equatation

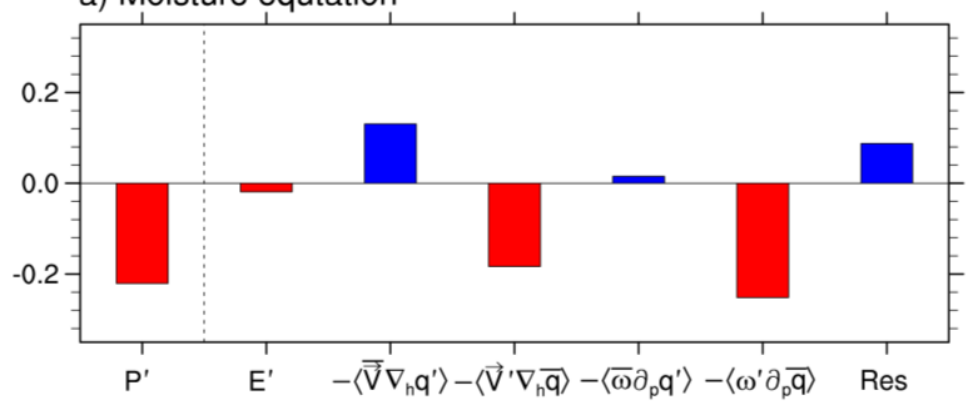

b) MSE equataion

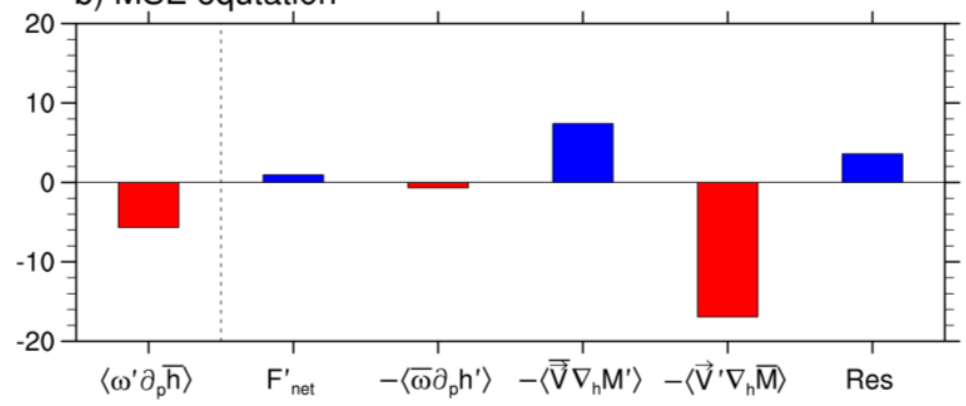

Fig. 2. Budget analysis of the (a) moisture ( $\mathrm{mm} /$ day) and (b) MSE (W/m²) equations for the area $34^{\circ} \sim 42^{\circ} \mathrm{N}, 102^{\circ} \sim 120^{\circ} \mathrm{E}$ (black dashed box in Fig. 1b) in composite El Niño developing summer. 

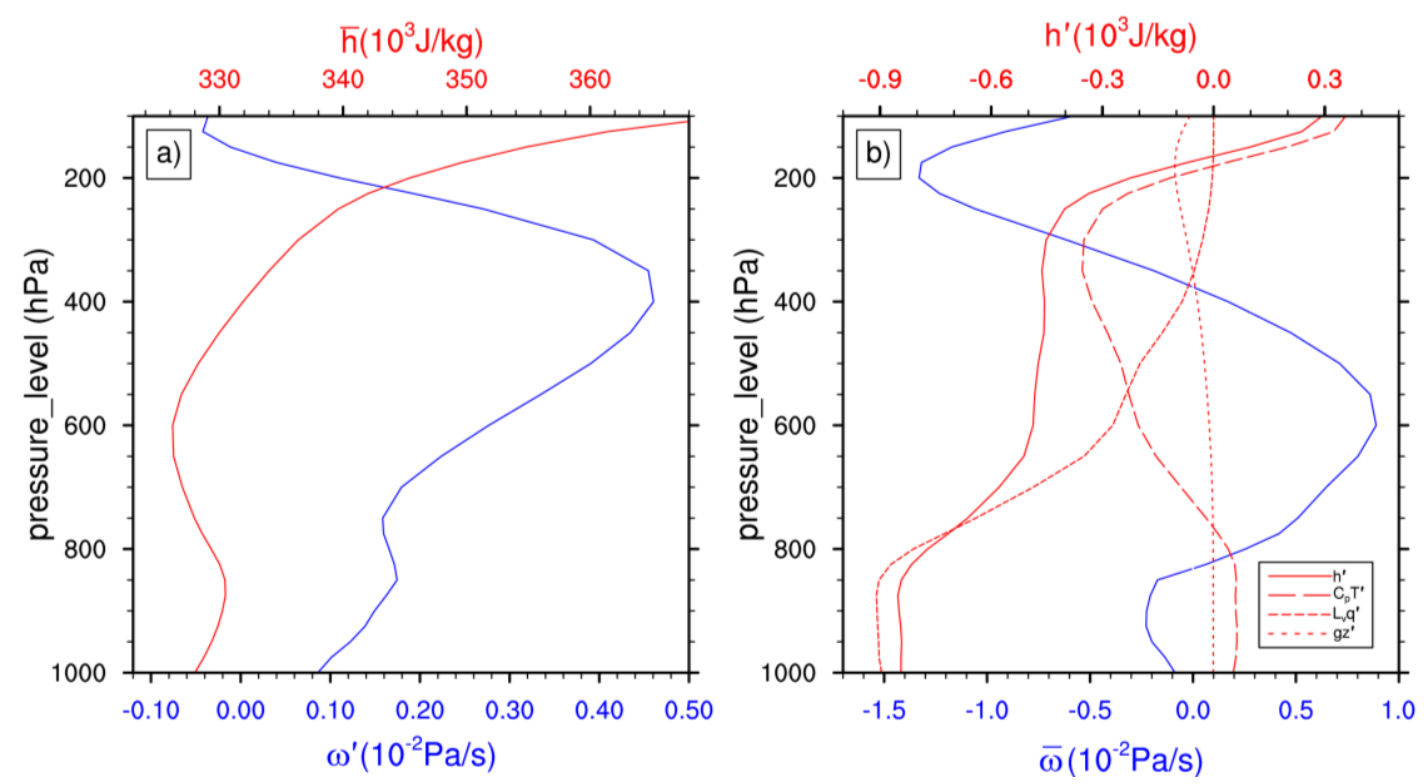

Fig. 3. Vertical profiles of (a, left) $\omega^{\prime}$ (blue line; $10^{-2} \mathrm{~Pa} / \mathrm{s}$ ) and climatological MSE (red line; $10^{3} \mathrm{~J} / \mathrm{kg}$ ), (b, right) $\bar{\omega}$ (blue line; $10^{-2} \mathrm{~Pa} / \mathrm{s}$ ), $h^{\prime}$ (red solid line; $10^{3} \mathrm{~J} / \mathrm{kg}$ ), $c_{P} T^{\prime}$ (red dashed line; $10^{3} \mathrm{~J} / \mathrm{kg}$ ), $L_{v} q^{\prime}$ (red short dashed line; $10^{3} \mathrm{~J} / \mathrm{kg}$ ) and $g z^{\prime}$ (red dotted line; $10^{3} \mathrm{~J} / \mathrm{kg}$ ) averaged over $34^{\circ} \sim 42^{\circ} \mathrm{N}, 102^{\circ} \sim 120^{\circ} \mathrm{E}$ (black dashed box in Fig. 1b) during El Niño developing summer. 


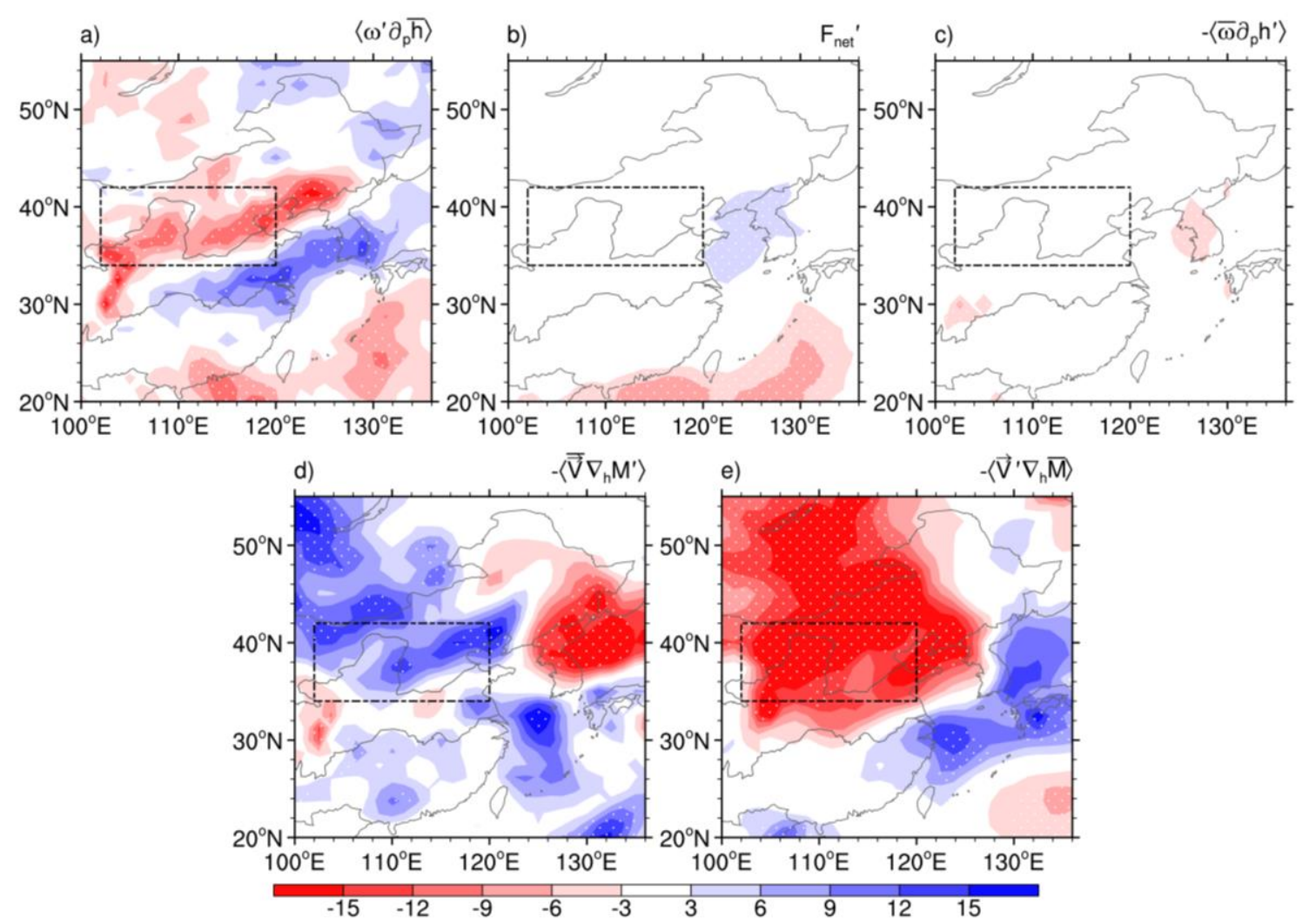

Fig. 4. Spatial distribution of MSE equation terms in composite El Niño developing summer. (a) Vertical advection of climatological MSE by anomalous vertical velocity, (b) net energy flux into the atmosphere, (c) vertical advection of anomalous MSE by climatological vertical velocity, (d) horizontal advection of anomalous moist enthalpy by climatological wind, and (e) horizontal advection of climatological moist enthalpy by anomalous wind. Values reaching the $10 \%$ significance level are stippled with white dots. Units are $\mathrm{W} / \mathrm{m}^{2}$. 

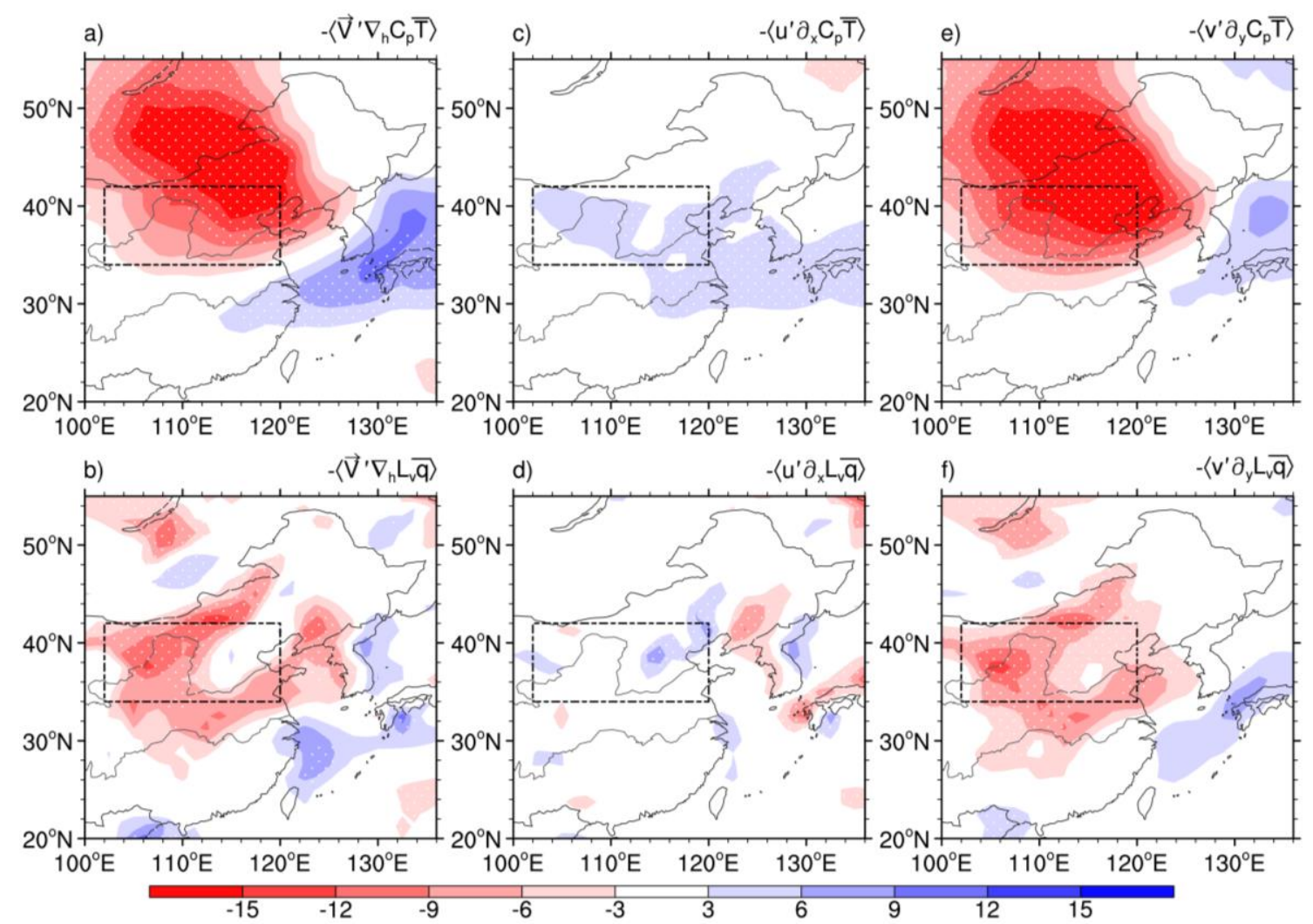

Fig. 5. Spatial distribution of horizontal advection of (a, top) climatological dry enthalpy by anomalous wind, and (b, bottom) climatological latent heat by anomalous wind in composite El Niño developing summer. Their zonal and meridional components are plotted in the middle (c, $d$ for zonal) and right (e, f for meridional) panels, respectively. Values reaching the $10 \%$ significance level are stippled with white dots. Units are $\mathrm{W} / \mathrm{m}^{2}$. 

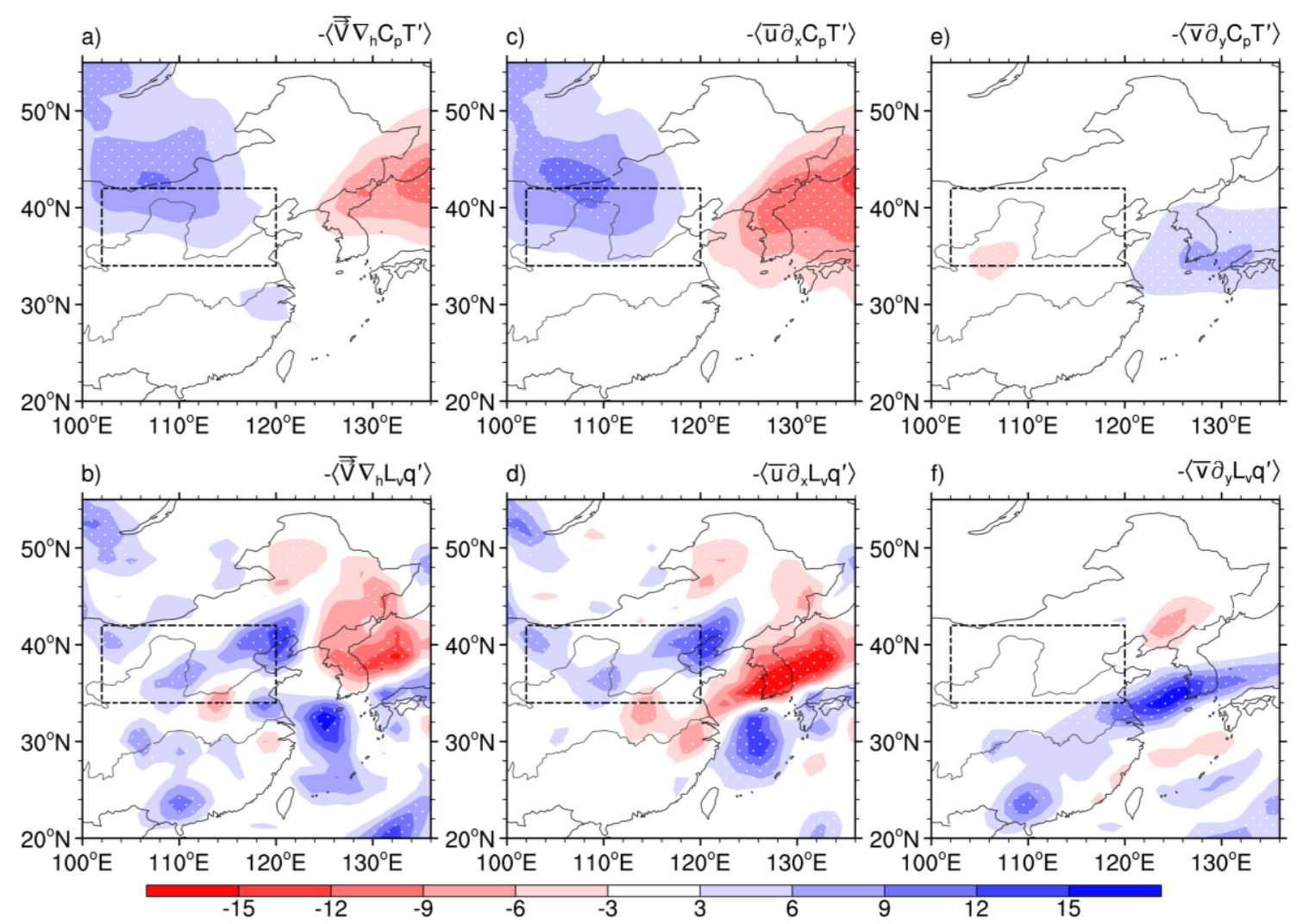

Fig. 6. Spatial distribution of horizontal advection of (a, top) anomalous dry enthalpy by climatological wind, and (b, bottom) anomalous latent heat by climatological wind in composite El Niño developing summer. Their zonal and meridional components are plotted in the middle ( $\mathrm{c}, \mathrm{d}$ for zonal) and right (e, $\mathrm{f}$ for meridional) panels, respectively. Values reaching the $10 \%$ significance level are stippled with white dots. Units are $\mathrm{W} / \mathrm{m}^{2}$. 

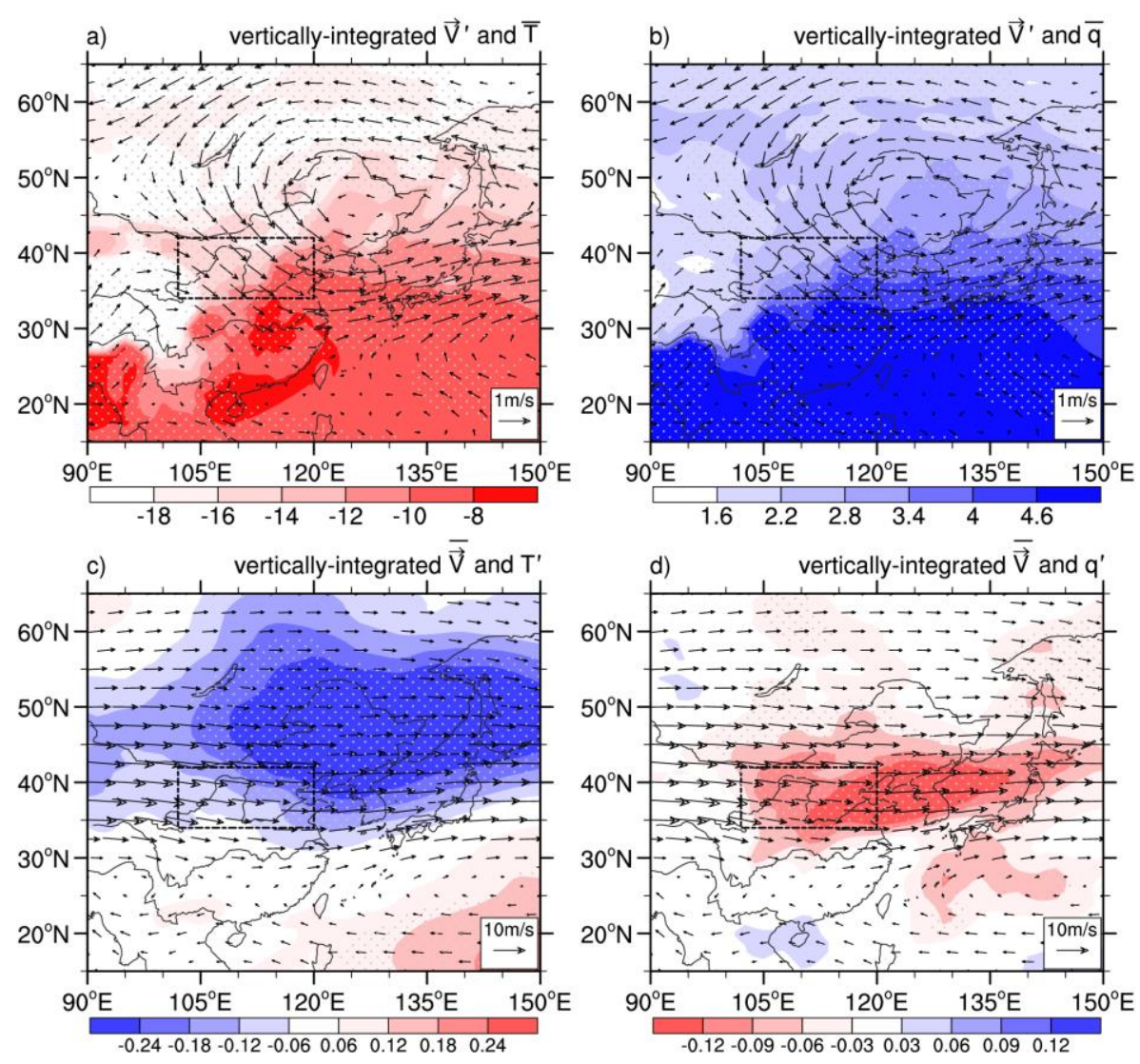

Fig. 7. Spatial distribution of vertically-integrated (a) wind anomaly (vector, $\mathrm{m} / \mathrm{s}$ ) and climatological air temperature (shadow, ${ }^{\circ} \mathrm{C}$ ), (b) wind anomaly (vector, $\mathrm{m} / \mathrm{s}$ ) and climatological specific humidity (shadow, g/kg), (c) climatological wind (vector, $\mathrm{m} / \mathrm{s}$ ) and air temperature anomaly (shadow, ${ }^{\circ} \mathrm{C}$ ), and (d) climatological wind (vector, $\mathrm{m} / \mathrm{s}$ ) and specific humidity anomaly (shadow, $\mathrm{g} / \mathrm{kg}$ ) in composite El Niño developing summer. 


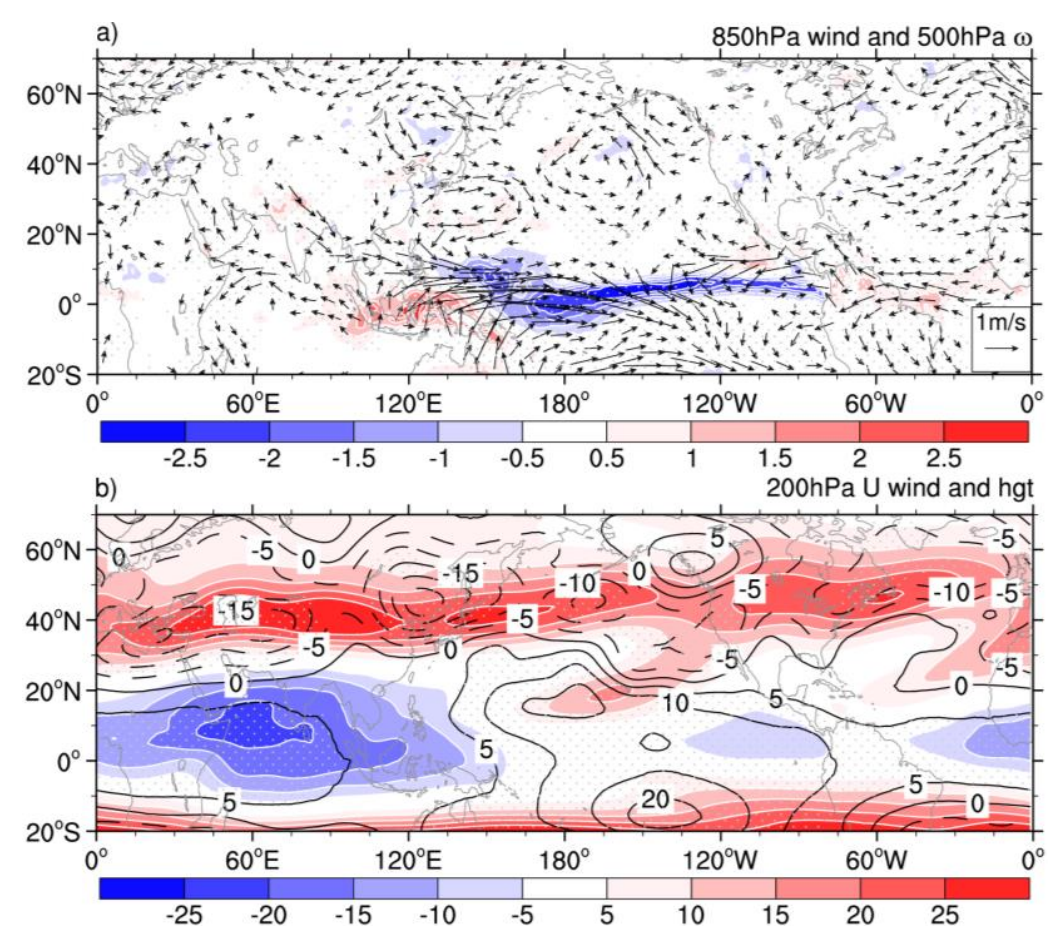

Fig. 8. (a) $850-\mathrm{hPa}$ wind anomalies (vector, $\mathrm{m} / \mathrm{s}$, only show greater than $0.25 \mathrm{~m} / \mathrm{s}$ ) and $500-\mathrm{hPa}$ vertical velocity anomalies (shading, $10^{-2} \mathrm{~Pa} / \mathrm{s}$ ), and (b) $200-\mathrm{hPa}$ geopotential height anomalies (contour, gpm) and climatological zonal wind (shading, m/s) in composite El Niño developing summer. 


\section{Appendix Figures Captions:}

Table A1. Non-El Niño summers with significant precipitation anomalies in Northern China

\begin{tabular}{c|cccccc}
\hline Category & \multicolumn{6}{c}{ Events } \\
\hline Dry years (4) & 1968 & 1980 & 1983 & 1986 & & \\
\hdashline Wet years (6) & 1976 & 1979 & 1994 & 1996 & 2003 & 2012 \\
\hline
\end{tabular}


a) Moisture equation

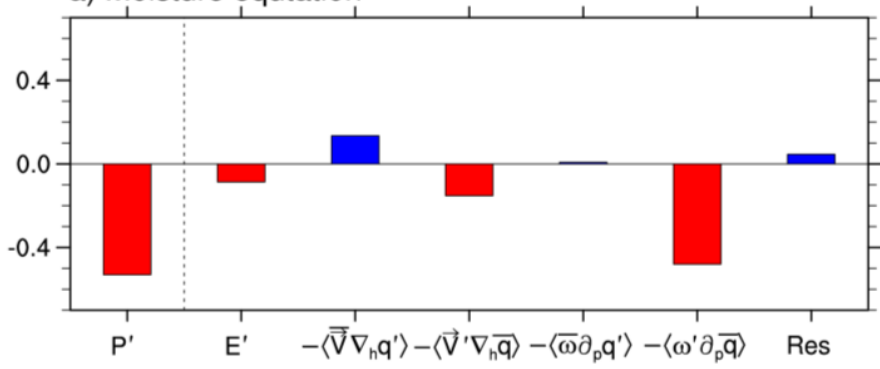

b) MSE equtation

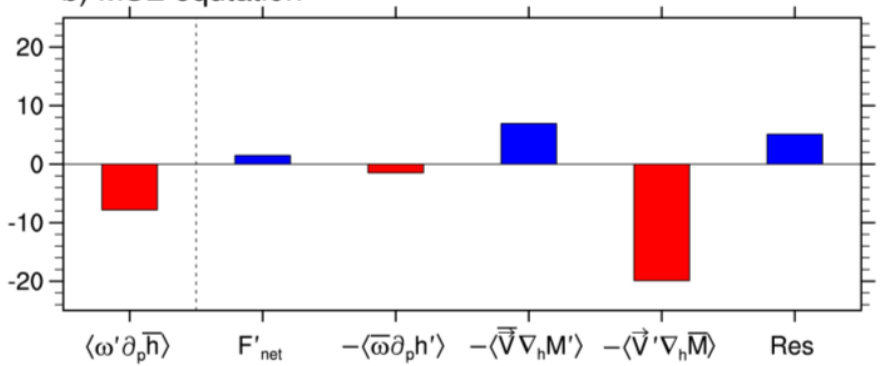

Fig. A1. Budget analysis (as in Fig. 2) of the (a) moisture (mm/day) and (b) MSE $\left(\mathrm{W} / \mathrm{m}^{2}\right.$ ) equations for the area $34^{\circ} \sim 42^{\circ} \mathrm{N}, 102^{\circ} \sim 120^{\circ} \mathrm{E}$ (black dashed box in Fig. 1b). Results shown are from a composite analysis with dry-minus-wet years excluding El Niño years.
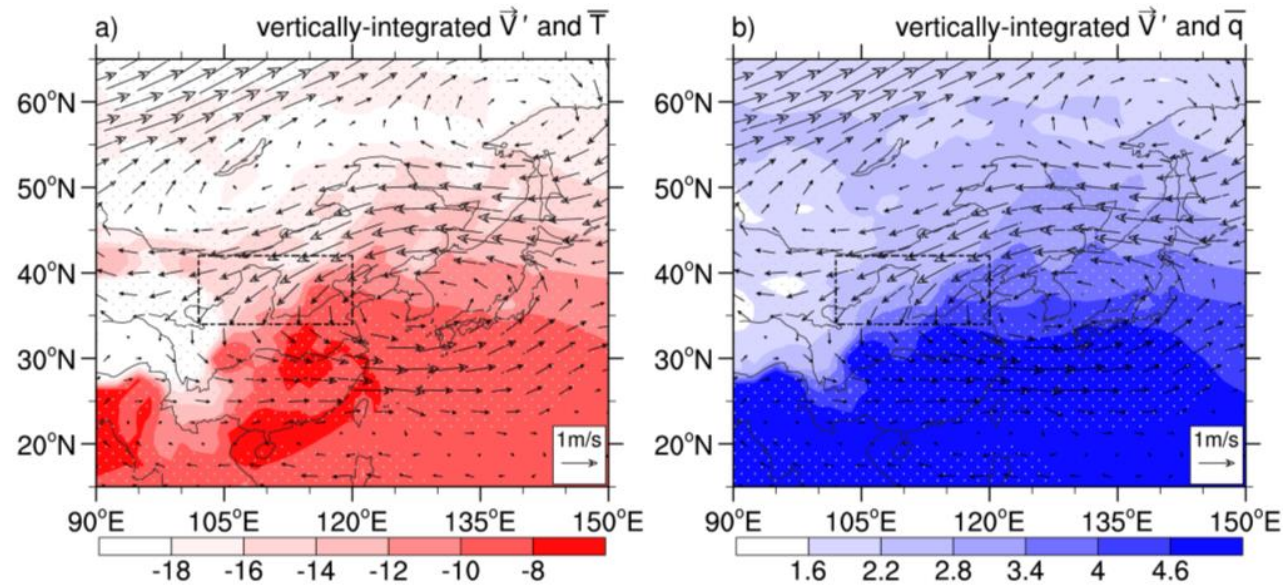

Fig. A2. Spatial distribution of vertically-integrated (a) wind anomaly (vector, $\mathrm{m} / \mathrm{s}$ ) and climatological air temperature (shadow, ${ }^{\circ} \mathrm{C}$ ), (b) wind anomaly (vector, $\mathrm{m} / \mathrm{s}$ ) and climatological specific humidity (shadow, $\mathrm{g} / \mathrm{kg}$ ). Results obtained from a composite analysis with dry-minus-wet years excluding El Niño years. 